\title{
Stepping Back and Leaping Forward
}

\author{
Daniel E. O'Sullivan
}

\begin{abstract}
$\mathrm{B}_{\mathrm{E}}$
eginning with this issue, 8.i, Textual Cultures moves to the online, open-access platform managed by IUScholarWorks. Consequently, the studies henceforth bearing the imprimatur of the Society of Textual Scholarship may reach a worldwide audience without the restrictions of paid subscriptions or passwords. Open access, however, does not lead to a loosening of editorial standards. Peer evaluation and careful collaboration among authors and editors will remain hallmarks of the work contained within the journals "pages", that is, its electronic pages, for the convention of pagination will be retained for ease of citation.

An online format provides a convenient milieu for discussions of hypertextuality, image/text relations, film studies, music, and other fields that rely on technologies to which the printed medium proves less conducive. Moreover, as those who work in digital editing and the creation of digital databases make improvements to their projects and techniques, pulling examples from those powerful tools into articles in Textual Cultures will be effortless. The articles contained in the inaugural online issue make use of hyperlinks as well as PowerPoint slides, and soon we hope to include music and video files, 3D model files, and anything else that might come down the fiber-optic highway.

When moving forward, it is wise to step back and assess the situation in which we find ourselves. I was reminded of this just recently, during a research trip. Christopher Callahan (Illinois-Wesleyan University), MarieGeneviève Grossel (Université de Valenciennes), and I are producing an edition of the melodies and texts of the songs of Thibaut de Champagne (d. 1253). Most of Thibaut's manuscripts are catalogued in Paris, and the major
\end{abstract}


sources have been filmed and put online as digital facsimiles. One manuscript, however, is not readily available from a distance: British Library, Egerton MS 274, admittedly a minor source for its contribution to Thibaut's corpus. However, in the interest of scholarly thoroughness, I traveled to London in October 2013 to study the manuscript.

Upon asking to see the codex, I was informed that it would take at least an hour before it arrived, so I set about consulting secondary literature in the reading room. The entry in the British Library print catalogue for Egerton 274 provides only a short paragraph acknowledging its inclusion in the collection. The British Library online publishes a more detailed description, which appeared reasonable at first glance, and I felt satisfied that I would have something of a roadmap to follow when the manuscript appeared in front of me. Upon further investigation, however, I discovered another description published by the Digital Image Archive of Medieval Music, which in this case reproduces verbatim the description from the Répertoire International des Sources Musicales. DIAMM links to digital facsimiles of the print publication here and here. At first blush, the DIAMM/RISM description appeared substantially longer, and I initially assumed that this account would supplement the first. I felt dismay, however, as I began to compare the two.

The British Library online catalog breaks the codex down into two "parts": cc. 3r-118v and cc. 119r-132v (cc.1-2 are flyleaves). This struck me as quite odd, for below this two-part description, the site claims that the manuscript is composed of 160 not 132 folios. On how the remaining quires and folios might fit into the rest of the codex's structure, the catalog falls silent.

According to DIAMM/RISM, the manuscript is divided into six "fascicles" accounting for 160 folios. ${ }^{1}$ When the manuscript arrived at my assigned seat, I began the painstaking process of codicological analysis, and I came to a conclusion: both descriptions were misleading, if not outright wrong. I counted 22 quires with one interpolated folio and discovered evidence both for and against the division of the codex into six fascicles. For example, quires I-VII are all linked together, not by catchwords, but by custodes in the music and by virtue of the positive or probable attribution

1. The notion of fascicle being rather somewhat nebulous in this context, it wasn't until I found Pamela Kay Whitcomb's dissertation on Egerton 274 that I realized that these divisions were put in place by the venerable medieval musicologists Friedrich Ludwig and Friedrich Gennrich. Apparently, this young scholar did not feel comfortable contradicting these giants of twentieth-century musicology and only tweaked her own description to solve a particular problem of one piece's place in the codex (Wнітсомв 2000, 8). 
of most songs to Philip the Chancellor. However, the status of quire VIII, which DIAMM/RISM places into the first fascicle, is problematic. A regular quaternion, quire VIII contains more Latin songs, but no custodes connect this quire with the preceding gatherings. While attributions to Philip remain plausible, the polyphonic nature of most of the songs in this quire set it apart from the predominately monophonic offerings in quires I-VII. In other words, while there are reasons for grouping quire VIII with the preceding gatherings on one level, on a more basic codicological level, there are reasons to set it apart, considerations that DIAMM/RISM obscure.

The moral of the story is that while terabytes of information are only a keystroke away - descriptions, facsimiles, and secondary sources - we must ever retain our scholarly skepticism. It might seem odd that in launching the online version of a journal the editor would risk undercutting the authority of the online format. That is not the intention here. Rather, it is to acknowledge two related ideas: one, archival research may remain necessary today not in spite of but because of what is available digitally, for we risk placing removing ourselves more than ever from the materiality of the texts we study. We may be tempted to "make do" with facsimiles and thereby close ourselves off to a full experience of the text. The ability to access information online can help us prepare ourselves better for visits to the archives, but it can never replace those visits. The editors hope that Textual Cultures will help prepare scholars for that research and, in turn, quickly and easily disseminate the knowledge obtained during those visits to the scholarly world.

The second acknowledgment concerns the form in which articles published in Textual Cultures will take. In the world of wikis, crowd-sourcing, and online databases, all useful inventions and undertakings, to be sure, periodic updates are laudable. However, the articles and reviews published in Textual Cultures do not constitute catalog and database entries: rather, they represent synthetic, reflective pieces of scholarship. The editors of Textual Cultures have made a conscious decision to resist the temptation of continuous updates to its published material; articles published online henceforth will constitute their "form of record". As always, authors may build upon that material in subsequent publications within Textual Cultures and elsewhere. However, if authors and editors have it in the back of their minds that something can always be changed, tweaked, or excised, it is the opinion of the editors that careless writing or editing may ensue. It is hoped that our policy will help both authors and editors focus on producing excellent scholarship the first time around. Moreover, as Textual Cultures will remain distributed by such entities as JSTOR and Project MUSE, and 
perhaps others in the future, the feasibility of making every desired change for every version diminishes.

Articles in the inaugural digital issue of Textual Cultures come in two clusters, each of which attests to the broad field of textual studies that the Society of Textual Scholarship investigates. "Editing Options" juxtaposes two discussions of fluidity in editing texts, both medieval and modern. $\mathrm{H}$. Wayne Storey muses on "local options" in manuscript witnesses. Anchoring his discussion in the transmission of a poem in Old Occitan by Raimbaut de Vaqueiras and two poems by Petrarch, Storey concludes on the importance of the dialectic between fluidity and fixity for understanding the compositional and compilational strategies in the Rerum vulgarium fragmenta. Storey's medieval examples dovetail remarkably well with Dirk van Hulle's thoughts on a hypertextual edition of Samuel Beckett in which readers will, through technological innovation, be able to select options among variants, corrections, and "un-corrections" that only a genetic approach to editing can lay out for the reader.

The second cluster, curated by Marta Werner, is entitled, "Crossed Codes: Print's Dream of the Digital Age, Digital's Memory of the Age of Print", the same title as the MLA session that Werner chaired in January 2013 on behalf of the MLA Committee on Scholarly Editions. Jonathan Baillehache's piece on electronic poetry and the avant-garde sensibilities of the Surrealists and Dadaists plays off of Andrew Ferguson's investigation of "playerly" texts in the forms of poetry, narrative, and video games. Gabrielle Dean's comments on Gangerization - the practice of tipping and pasting in of extra-textual content into already published books through a kind of associative logic prefigures, in fact, the hypertextuality that both Baillehache and Ferguson probe. At the same time, while Dean folds questions of textual integrity into her historical study, Kari Kraus and her students - Charity Hancock, Clifford Hichar, Carlea Holl-Jensen, Cameron Mozafari, and Kathryn Skutlin - report on their creation of new textual histories based in a notion they call "bibliocircuitry", a term meant to encapsulate concepts of reflective design in book making.

The book review section features three offerings, all edited by a new member of the editorial team of Textual Cultures, Heather Allen of the University of Mississippi. Allen brings her own expertise in Mesoamerican studies to bear on the review section while continuing to address other issues of long-time interest to members of the Society for Textual Scholarship and their colleagues.

In conclusion, the editors of Textual Cultures are proud of its association with IUScholarWorks, which will enable members of the Society of Tex- 
tual Scholarship and their colleagues to reach a wider audience of textual scholars, students, and enthusiasts. We look forward to future scholarly exchanges on the textual past and future, on looking back while leaping forward.

\section{Works Cited}

British Library. 2013. "Detailed Record of Egerton 274", http://www.bl.uk/catalogues/illuminatedmanuscripts/record.asp?MSID $=7878 \&$ CollID $=28 \& N S t a r t=274$, accessed 13 December 2013.

Dittmer, Luther. 1964. Reprint of Ludwig 1910. Musicological Studies 7: 243-63.

GennRich, Friedrich. 1925. "Die altfranzösische Liederhandschrift London, British Museum, Egerton 274", Zeitschrift fur romanische Philologie 45: 402-44.

LuDwIG, Friedrich. 1910. Repertorium organorum recentioris el motetorum vetustissimi stili, Bd. I, Abt. 1: Catalogue Raisonne der Quellen: Handschriften in Quadrat-Notation, Halle.

"London British Museum, Egerton 274", Répertoire international des sources musicales. http://images.cch.kcl.ac.uk/diamm/liv/rism/mainpages/1-497.png, accessed 13 December 2013; http://images.cch.kcl.ac.uk/diamm/liv/rism/mainpages/1-498.png, accessed 13 December 2013.

"Source: GB-Lbl Egerton 274, Trouvèvre [sic] songbook with a few polyphonic additions, 13th, 14th, 15th centuries; provenance: France", Digital Internet Archive of Medieval Music, 2012. King's College London, http://www.diamm.ac.uk/isp/Descrip tions?op=SOURCE\&sourceKey=916, accessed 13 December 2013.

Wнітсомв, Pamela Kay. 2000. "The Manuscript London, British Library, Egerton 274: A Study of Its Origin, Purpose, and Musical Repertory in Thirteenth-Century France", Ph.D. dissertation, University of Texas, Austin. 